\title{
Outcome of surgical management of genital prolapse in the obstetric gynecology department of the Ignace Deen Hospital in Conakry, Guinea
}

\author{
Abdourahamane Diallo ${ }^{1,2 *}$, Telly $\mathrm{Sy}^{1,2}$, Ibrahima Sory Balde ${ }^{1,2}$, Ibrahima Koussy Bah ${ }^{1,2}$, \\ Ibrahima Conte ${ }^{1,2}$, Ibrahima Amadou Diallo ${ }^{1,2}$, Namory Keita ${ }^{2,3}$
}

\begin{abstract}
${ }^{1}$ Department of Gynecology-Obstetrics of the Ignace Deen National Hospital of Conakry University Hospital, Guinea ${ }^{2}$ Faculty of Health Sciences and Techniques of Gamal Abdel Nasser University of Conakry, Guinea

${ }^{3}$ Department of Gynecology-Obstetrics of the Donka National Hospital of Conakry University Hospital, Guinea
\end{abstract}

Received: 15 March 2020

Accepted: 04 April 2020

\section{*Correspondence:}

Dr. Abdourahamane Diallo,

E-mail: adiallo69gn@yahoo.fr

Copyright: (c) the author(s), publisher and licensee Medip Academy. This is an open-access article distributed under the terms of the Creative Commons Attribution Non-Commercial License, which permits unrestricted non-commercial use, distribution, and reproduction in any medium, provided the original work is properly cited.

\section{ABSTRACT}

Background: Each year several patients are operated on for genital prolapse in our department, but no study has yet been done to analyse the results. The objective of this study was to highlight the operating techniques used and to analyse the anatomical and functional outcomes.

Methods: It was an observational, longitudinal, prospective and descriptive study which took place over a period of 2 years in the department of obstetrics and gynecology of the Ignace Deen hospital de Conakry in Guinea. This study focused on patients operated on in the department for genital prolapse.

Results: During the study period, 67 patients underwent genital prolapse surgery in the department. The operating techniques used are the triple perineal operation or, associated with colposuspension and/or Richter or Mc Call, Richardson's operation, Rouhier's operation and promonto-fixation. This study recorded in the follow up a case of recurrence of hysterocele one year after a Richardson operation, a correction of all digestive and sexual functional disorders and a correction of $81.25 \%$ of functional urinary disorders. The intraoperative complications were a rectal wound, two bladder wounds and three cases of hemorrhage requiring blood transfusion. The post-operative results were good in $98.5 \%$ of the cases.

Conclusions: The lower approach is the main route used for surgical treatment of prolapse. The anatomical and functional results obtained are encouraging.

Keywords: Assessment, Ignace Deen, Prolapse, Surgical, Treatment

\section{INTRODUCTION}

Prolapse is defined as a protrusion, permanent or on exertion, in the vaginal lumen, at or outside the vulvar opening, of all or parts of the vaginal walls more or less lined with the bladder, rectum and adjacent peritoneal cul de sac, as well as the vaginal fundus secured to the cervix. ${ }^{1}$ The pathophysiology of pelvic static disorders remains, to this day, not fully understood. Physiological aging and multiparity are considered by most authors to be the major determinants of these disorders. The hypothesis of a degeneration of the connective tissue is often put forward, with alteration of the biosynthesis of collagen and / or elastin leading to a loss of elasticity of the muscle fibers. ${ }^{2}$ The onset of prolapse is enhanced by the number of pregnancies and deliveries, birth weight, family history and history of hysterectomy and vulvectomy. ${ }^{3}$ 
It affects around 55\% of women over the age of 50 and is often associated with functional urinary disorders (incontinence, pollakiuria, urgenturia, dysuria), digestive disorders (dyschesia, anal incontinence, constipation) or genitals complaints (dyspareunia, metrorrhagia). ${ }^{1}$ Genital prolapse is one of the most common indications for functional gynaecological surgery, affecting up to $50 \%$ of women who have given birth. ${ }^{4}$ According to Lansac, $11 \%$ of women over the age of 70 have prolapse surgery. ${ }^{1}$ Surgical treatment remains the standard treatment for genital prolapse, but can be the cause of several intra- and postoperative complications that potentially affect the quality of life of women. Intraoperative complications are dominated by bladder and rectal wounds and haemorrhages, while postoperative complications include retained urine, pelvic hematomas, pelvic abscesses, phlebitis, perineal pain and sciatica. ${ }^{5-10}$ There is a significant decrease in sexual desire, frequency of orgasms, arousal and an increase in dyspareunia. ${ }^{5}$ In the department, each year several patients are operated on for genital prolapse, but no study has yet been done to analyse this practice pattern. The aim of this study was to highlight the operating techniques used and to analyse their anatomical and functional results.

\section{METHODS}

It was an observational, longitudinal, prospective and descriptive study which took place over a period of 3 years in the gynecology-obstetrics department of the Ignace Deen National Hospital at the Conakry University Hospital Center in Guinea. This study focused on patients admitted to the department for genital prolapse.

\section{Inclusion criteria}

- All patients operated on for genital prolapse in the department during the study period and who agreed to participate in the study were included in the study.

\section{Exclusion criteria}

- All patients admitted to the department for genital prolapse who benefited from non-surgical treatment were not included

- All patients operated on for genital prolapse in the department but who did not agree to participate in the study were excluded from the study.

Sampling: an exhaustive recruitment of all patients meeting the inclusion criteria was carried out.

Data collection was done using a pre-established form according to the objectives of the study. These data were collected by interview and observation of the examination and patient management.

The analysis focused on age, gyneco-obstetric history (number and mode of delivery, large fetus, history of perineal tear and prolapse and menopause), pregnancy desire and sexual intercourse, type and degree of prolapse according to the French classification and the Pop-Q classification, voiding disorders and defecation associated with prolapse, the surgical technique performed, per and postoperative complications and the patient's quality of life after the operation.

For follow-up, patients were asked to return to the ward six and twelve months after their discharge from the Hospital and then annually. Between these appointments, orders were given to immediately report any abnormalities to the medical team. During follow-up, there was systematically performed, for all patients, a clinical interview and complete physical examination.

\section{Statistical analysis}

The data were analyzed with software $\mathrm{R}$ version 3.4.2. The descriptive analysis consisted of calculating proportions for the qualitative variables; means, standard deviations and extremes for the quantitative variables.

\section{RESULTS}

During the study period, 67 cases of genital prolapse (stage 3 and 4) were operated on in the department.

Table 1: Age distribution in the series.

\begin{tabular}{|lll|}
\hline Age (year) & Numbers $(\mathbf{n = 6 7})$ & Percentage \\
\hline $20-30$ & 3 & $4.5 \%$ \\
\hline $31-40$ & 7 & $10.4 \%$ \\
\hline $41-50$ & 6 & $9.0 \%$ \\
\hline $51-60$ & 17 & $25.4 \%$ \\
\hline $61-70$ & 25 & $37.3 \%$ \\
\hline $71-80$ & 7 & $10.4 \%$ \\
\hline 81 et + & 2 & $3.0 \%$ \\
\hline Total & 67 & $100.0 \%$ \\
\hline
\end{tabular}

Mean age: $58.63 \pm 13.5$ years, extremes 25 and 86 years.

\section{Age distribution}

The average age of the patients was $58.63 \pm 13.5$ years (range 25 and 86 years) with a predominance of the age group from 61 to 70 years. (Table 1). Study of the distribution according to gynaecological and obstetrical history revealed an average parity of 6.69 and extremes of 0 and 13 with a predominance of large multiparous women (67\%). Among the 67 operated patients, $68.7 \%$ had given birth to a large fetus, $97 \%$ had had a perineal tear during childbirth, $4 \%$ had already been operated once for genital prolapse and $77.6 \%$ were postmenopausal (Table 2 ).

\section{Distribution of patients according to desire for children and sexual intercourse}

Among the 15 postmenopausal women, 8 (53\%) wanted to have one and the other $7(47 \%)$ did not want any more. In terms of desire for sex, 36 women $(54 \%)$ wanted to 
continue having sex compared to 31 (46\%) who no longer wanted to have sex.

Table 2: Patients distribution according to obstetrical history.

\begin{tabular}{|lll|}
\hline $\begin{array}{l}\text { Past obstetrical } \\
\text { history }\end{array}$ & $\begin{array}{c}\text { Number } \\
(\mathbf{n}=7)\end{array}$ & Percentage \\
\hline Vaginal delivery & & \\
\hline 0 & 3 & $4.5 \%$ \\
\hline $1-3$ & 10 & $14.9 \%$ \\
\hline $4-5$ & 9 & $13.4 \%$ \\
\hline 6 et + & 45 & $67.2 \%$ \\
\hline Mean: 6.69 & SD: 2.8 & $\begin{array}{l}\text { Extremes: } \\
0 \text { and } 13\end{array}$ \\
\hline Macrosomia & & \\
\hline Yes & 46 & $68.7 \%$ \\
\hline No & 21 & $31.3 \%$ \\
\hline & $\mathrm{SD}: 304.1$ & $\begin{array}{l}\text { Extremes: } \\
4050 \mathrm{~g} \text { and }\end{array}$ \\
\hline Mean weight: $4400 \mathrm{~g}$ & $\mathrm{~g}$ & $4600 \mathrm{~g}$ \\
\hline Perineal tear & & \\
\hline Yes & 65 & $97.0 \%$ \\
\hline No & 2 & $3.0 \%$ \\
\hline Genital prolapse & & \\
\hline Yes & 4 & $6.0 \%$ \\
\hline No & 63 & $94.0 \%$ \\
\hline Menopause & & $77.6 \%$ \\
\hline Yes & 52 & $22.4 \%$ \\
\hline No & 15 & \\
\hline & & \\
\hline
\end{tabular}

\section{Distribution of patients according to the degree of prolapse}

\section{$P O P-Q$ classification}

A total 63 cases of prolapse $(95.5 \%)$ in the $3^{\text {rd }}$ stage and 3 cases $(4.5 \%)$ in the $4^{\text {th }}$ stage was noted. Stages 1 and 2 did not benefit from surgical treatment.

\section{French classification}

The $3^{\text {rd }}$ degree with 61 cases $(92.4 \%)$ was the most frequent followed by the 4 th degree with 5 cases $(7.6 \%)$.

\section{Distribution of patients according to the type of prolapse}

There were 65 cases (29\%) of hysterocele, 62 cases $(27 \%)$ of cystocele, 59 cases $(26 \%)$ of rectocele and 41 cases $(18 \%)$ of elytrocele.

\section{Distribution according to associated functional disorders}

The distribution of operated patients according to associated functional disorders showed that $16.4 \%$ of patients had urinary incontinence, $26.9 \%$ dysuria, $4.5 \%$ retention of urine, $7.5 \%$ dyschesia and $20,9 \%$ dyspareunia (Table 3).
Table 3: Patient distribution according to associated functional troubles.

\begin{tabular}{|c|c|c|}
\hline Troubles & Number $(n=67)$ & Percentage \\
\hline \multicolumn{3}{|c|}{ Urinary incontinence } \\
\hline Yes & 11 & $16.4 \%$ \\
\hline No & 56 & $83.6 \%$ \\
\hline \multicolumn{3}{|l|}{ Dysuria } \\
\hline Yes & 18 & $26.9 \%$ \\
\hline No & 49 & $73.1 \%$ \\
\hline \multicolumn{3}{|c|}{ Urinary retention } \\
\hline Yes & 3 & $4.5 \%$ \\
\hline No & 64 & $95.5 \%$ \\
\hline \multicolumn{3}{|l|}{ Dyschésia } \\
\hline Yes & 5 & $7.5 \%$ \\
\hline No & 62 & $92.5 \%$ \\
\hline \multicolumn{3}{|c|}{ Dyspareunia } \\
\hline Yes & 14 & $20.9 \%$ \\
\hline No & 53 & $79.1 \%$ \\
\hline
\end{tabular}

\section{Distribution of patients according to the operating} techniques used

Regarding the operating techniques used, $4.5 \%$ of patients underwent promontofixation, $49.3 \%$ a triple perineal operation (TPO), 20.9\% a TPO associated with colposuspension, 3\% a Richardson operation, $10.4 \%$ a Rouhier operation, 3\% a TOP associated with a colposuspension and a sacrospinofixation of Richter, $4.5 \%$ a TOP plus colposuspension and Mc Call and $4.5 \%$ a TPO plus Mc Call (Table 4).

The post-operative follow-up was unremarkable for 66 patients $(98.5 \%)$ and enamelled with both hemorrhage and infection for 1 patient.

Antibiotic prophylaxis: it was systematic for all patients with $1 \mathrm{~g}$ of ceftriaxone.

The mean hospital stay was $4.7 \pm 1.2$ days with extremes of 2 and 9 days. The average duration of follow-up of operated patients is 13.4 months with extremes of 6 and 24 months.

\section{Results of treatment}

Anatomically, there was a recurrence of a hysterocele a year later in one of the two patients who had benefited from Richardson's operation without having had a pregnancy. In terms of function, none of the 67 patients presented functional digestive disorders during follow-up after the intervention.

Table 4: Patient distribution according to the surgical report. 


\begin{tabular}{|lll|}
\hline Techniques & $\begin{array}{c}\text { Number } \\
(\mathbf{n = 6 7 )}\end{array}$ & Percentage \\
\hline Anaesthesia type & & \\
\hline Spinal anaesthesia & 64 & $95.5 \%$ \\
\hline General anesthesia & 3 & $4.5 \%$ \\
\hline Approach & & \\
\hline Vaginal route & 64 & $95.5 \%$ \\
\hline Abdominal route & 3 & $4.5 \%$ \\
\hline Surgical technique & & \\
\hline TOP & 33 & $49.3 \%$ \\
\hline TOP+Colposusprension & 14 & $20.9 \%$ \\
\hline Richardson procedure & 2 & $3.0 \%$ \\
\hline Rouhier procedure & 7 & $10.4 \%$ \\
\hline $\begin{array}{l}\text { Request an operation } \\
\text { with Richter }\end{array}$ & 2 & $3.0 \%$ \\
\hline $\begin{array}{l}\text { Request an appointment } \\
\text { with Mc Call }\end{array}$ & 3 & $4.5 \%$ \\
\hline Promontofixation & 3 & $4.5 \%$ \\
\hline TOP+Mc Call & 3 & $4.5 \%$ \\
\hline Intraoperative complications & 6 \\
\hline Yes & 61 & $91.0 \%$ \\
\hline No & $6 \%$ \\
\hline
\end{tabular}

*complications: 1 case of rectal lesion, 2 cases of bladder lesion and 3 cases of haemorrhage with blood transfusion. *TPO: triple perineal operation associating a vaginal hysterectomy, with an anterior and posterior Colpopérinéorrahia. Penta: TPO + Colposuspension + Richter or Mc Cole.

Dysuria was corrected in $88.89 \%$ of cases (16 cases/18), urinary incontinence in $63.64 \%$ of cases (7 cases/11) and retention of urine in $100 \%$ of cases (3 cases/3) with an overall correction of functional urinary disorders of $81.25 \%$ (26 cases/32). Persistence of stress urinary incontinence was noted in four patients and dysuria in two other patients.

Among the 14 patients who suffered from dyspareunia before surgery, the latter had disappeared in all (8) of the women who had resumed sexual intercourse. On the other hand, there was a new case of dyspareunia caused by the intervention in a patient who had benefited from a TOP plus a colposuspension six months before.

\section{DISCUSSION}

Genital prolapse mainly affects older women. The average age of women with prolapse reported in this study is lower than that reported by Kapella et al, who found an average age of 82.2 years with extremes of 80 and 95.6, and higher than the average age found by Nayama et al in Niger which was 37 years with $73 \%$ of women who were not menopausal. ${ }^{11}$ Tremollieres reports a progressive increase during aging, in the frequency of pelvic static disorders (including urinary and fecal incontinence, and genital prolapse), which went from $9.7 \%$ in women aged 20 to 39 , to $49.7 \%$ in those over 80 years old. ${ }^{2}$ The same observation was made by Estrade et al who reported during their study, a clear predominance of postmenopausal women of advanced age 5. At that age, there is a high frequency of comorbidities (cardiovascular diseases, diabetes) making any surgery difficult.

As in several studies, multiparas who gave birth to large fetuses, menopausal, with a history of perineal tear or a personal or family history of genital prolapse were the most affected. , $3,5,11^{2}$

Hysterocele and cystocele were discovered at late evolutionary stages because of the fact that in our culture everything related to the genitals is considered taboo, especially in older women. The same observation was made by Estrade and Guillibert. ${ }^{5,12}$

Functional urinary disorders were the most frequent. This observation is similar to that made by Estrade who reported $18.8 \%$ of patients with stress urinary incontinence associated with prolapse. ${ }^{5}$

The average length of stay reported in this study is similar to that reported by Rathat et al, which was five days. ${ }^{13}$

For the surgical treatment of genital prolapse in the department, several operating techniques are used. The choice of technique depended on the type and degree of prolapse and the woman's desire to have sex or become pregnant. Vaginal hysterectomy was systematic in all postmenopausal and premenopausal women who no longer wanted to have children. This same observation was made by Tebeu et al in Cameroon. ${ }^{14}$ That opinion is not shared by certain authors who report that hysterectomy does not improve the results of treatment for prolapse. ${ }^{15}$ According to Guillibert, hysterectomy should be avoided and the prescription of locally administered estrogens favored. ${ }^{12}$

For Le Normand et al. there is no reason to systematically perform a hysterectomy during prolapse surgery and Nayama et al, have performed conservative treatment in $65 \%$ of patients. ${ }^{11,16}$ On the other hand, Mansoor et al. because of the high frequency of cancerous and precancerous lesions of the cervical and uterine cancer of incidental discovery, recommend the practice of hysterectomy or, at least," assess the endometrium by hysteroscopy and biopsy curettage in case of uterine preservation. ${ }^{17}$ Kapella et al. reported $68.4 \%$ vaginal hysterectomy and one case of Richter sacrospinofixation during their study on prolapse surgery in the very elderly patient at Limoges University Hospital. ${ }^{6}$

Vaginal patency was maintained in women who wanted to have sex, and the vagina was closed in women who no longer wanted to have sex. For Menard et al., The triple perineal operation as well as sacrospinofixation represent an alternative to vaginal closure by colpocleisis to treat genital prolapse in women over 70 years old. ${ }^{7}$

In case of isolated uterine prolapse in premenopausal women who wanted to have children, Richardson's 
operation or promontofixation was performed. If the hysterocele is associated with a cystocele or a rectocele, Richardson's operation was supplemented by anterior and posterior colporraphy. Richardson's operation was chosen over Manchester's because of its improved fertility outcome. According to Delarue, Richardson's operation makes it possible, thanks to the absence of a cervical surgical step, to envisage a pregnancy later, unlike Manchester, which leads to impaired fertility by secondary cervical stenosis in the event of associated cervical resection and the increase in early abortions and premature deliveries. 18 In the event of an isolated hysterocele in a young woman without hypertrophic elongation of the cervix, Richardson's operation seems to be possible in the first intention. The same author emphasizes that promontofixation, in its diversity, remains the technique of choice for treating a woman under 50 years of age wishing to continue having sex because it causes less dyspareunia than the vaginal route. 18 The same opinion is divided by de Tayrac et al. who have reported that promontofixation is the gold standard that should be offered to young women.9 Demaria has shown that laparotomic promontofixation and vaginal sacro-spinofixation can be considered as reference techniques in the treatment of genital prolapse. ${ }^{19}$

The triple perineal operation was performed in the case of a combination of third- or fourth-degree cystocele without lateral fall, third or fourth degree hysterocele and first- or second-degree rectocele. It has been associated with Richter sacrospinofixation in cases of third- or fourthdegree rectocele and colposuspension in cases of third- or fourth-degree cystocele associated with lateral fall.

The anatomical and functional outcomes reported in this study are different from those reported by several authors. Mellier et al, recorded six cases of failure out of the 78 operated patients, two cases of recurrence, moderate dyspareunia in $13 \%$ of patients and disabling in two patients. The same author reported three cases of minor hemorrhage without blood transfusion, one rectal wound, two bladder wounds and three cases of hemorrhage. ${ }^{10}$ According to Niro et al, the onset of pain on D1 postoperatively is significantly more frequent in case of hysterectomy. ${ }^{20}$

Demaria et al, concluded that one third of women undergoing prolapse recurred within three to five years. ${ }^{19}$ Cravello et al reported intraoperatively, nine bladder wounds, three rectal wounds, eleven cases of hemorrhage and one ureteral plicature lesion during vaginal hysterectomy and postoperatively, three cases of vesicovaginal fistula, sixteen cases of secondary hemorrhage and thirty-six cases of urinary tract infections during vaginal hysterectomy. ${ }^{21}$ In the study by Lucot et al, the frequencies of bladder, urethral and ureteral wounds were $1.94,1.6$ and $1.55 \%$ respectively. ${ }^{15}$ In the study of Bui et al. the rate of intraoperative complications was $7 \%$ including two bladder wounds, a rectal wound and $4 \%$ of laparoconversions. ${ }^{8}$ Dia et al in Dakar reported one case of profuse intraoperative hemorrhage and three cases of bladder wound during surgical treatment of genital prolapse. $^{22}$ Sexual disorders are significantly more frequent after vaginal prolapse surgery. ${ }^{4}$ Chene et al showed satisfactory sexual function 24 months after surgery for $81.2 \%$ of patients. ${ }^{23}$ During the study by Estrade et al., the intraoperative complications were dominated by hemorrhage and rectal wounds and those postoperative by peri-vaginal hematomas and pelvic abscesses while the long-term symptomatology was marked by perineal pain, sciatica and dyspareunia. ${ }^{5}$ Kapella et al reported conversion to the upper route for hemorrhage, ligation of the right uretere and a recurrence of prolapse at six months. ${ }^{6}$

The efficacy of prolapse surgical treatment on functional urinary disorders reported in this study is confirmed by Cortesse et al, who have found that isolated prolapse treatment often alone can treat preoperative stress urinary incontinence. $^{24}$

The number of stress urinary incontinence associated with prolapse in our study does not allow us to confirm this assertion. Deval reported the disappearance of $87 \%$ of the symptoms of stress incontinence following the cure of prolapse by hysterocolpectomy with colpocleisis and Pizzoferrato et al found during their study, satisfactory anatomical and functional results in the short term..$^{25,26}$

Sergeant et al, propose to associate the retro-pubic TVT sub-urethral strip with the treatment of prolapse to better correct stress urinary incontinence. ${ }^{27}$ According to Marpeau, sub-urethral strips have simplified the treatment of urinary incontinence and certain prolapse can now benefit from prosthetic material by natural means. ${ }^{28}$

The lower route, as in several studies, was by far the most used. The lower route is associated with a higher frequency of sexual disorders than the upper route. 4 According to Boukerrou et al., The anatomical correction of prolapse by abdominal or vaginal route is comparable and satisfactory in the short term, and vaginal length or vaginal reorientation is not responsible. ${ }^{29}$ In the study by Letouzey et al, in laparoscopy or laparotomy, the most frequent complications in the intraoperative are bladder sores (10\%) hemorrhages $(3.9 \%)$ and postoperatively, vaginal erosions (3.4\%) and occlusions (4.6\%). Regarding vaginal surgery without prosthesis (sacrospinofixation), the most frequent complications are infections $(8.5 \%)$, urological complications $(3 \%)$, bleeding $(2.5 \%)$ and pain $(2 \%) .{ }^{30}$ For Lucot et al, The use of synthetic prostheses for the treatment of cystocele by the vaginal route offers better anatomical results than traditional surgery. ${ }^{15}$

\section{CONCLUSION}

Surgical treatment of prolapse is frequent in the department. The operating techniques used are multiple and depend on the type and degree of prolapse, the patient's age and her desire to have sex or become 
pregnant. The anatomical and functional results are good with the disappearance of all digestive and sexual functional disorders and $81.25 \%$ of functional urinary disorders. The rare intraoperative complications were marked by a rectal wound, two bladder wounds and three cases of haemorrhage requiring blood transfusion.

Funding: No funding sources

Conflict of interest: None declared

Ethical approval: The study was approved by the Institutional Ethics Committee

\section{REFERENCES}

1. Lansac J, Jacquet A. Genital prolapse. In: Gynecology for the practitioner. $9^{\text {th }}$ ed. France: Elsevier Masson; 2018:137-160.

2. Tremollieres F. Supportive connective tissue and genesis of prolapse. Obstet Gynecol Fertil. 2010;38(6):388-93.

3. Deval B, Rafii A, Polipot S, Aflack N, Levardon M. Prolapse of young women: study of risk factors. Gynecol Obstet Fertil. 2002;30(9):673-6.

4. Bouchet P, Crenn D, Deleflie M, Hocké C. Impact of genital prolapse surgery on the sexuality of patients. Gynecol Obstet Fertil. 2010;38(6):373-9.

5. Estrade JP, Agostini A, Roger V, Dallay D, Blanc B, Cravello L. Complications of sacrospinofixation. Gynecol Obstet Fertil. 2004;32(10):850-4.

6. Kapella M, Gana J, Safai K, Vincelot A, Aubard Y. Feasibility of vaginal prolapse surgery in the very elderly patient. Gynecol Obstet Fertil. 2005;33(11):857-60.

7. Menard JP, Mulfinger C, Estrade JP, Agostini A, Blanc B. Surgery for genital prolapse in women over 70 years of age: review of the literature. Gynecol Obstet Fertil. 2008;36(1):67-73.

8. Bui C, Ballester M, Chéreau E, Guillo E, Darai E. Functional results and quality of life after double laparoscopic promontofixation for the treatment of genital prolapse. Gynecol Obstet Fertil. 2010;38(10):563-8.

9. de Tayrac R, Letouzey V, Costa P, Haab F, Delmas V. Treatment of uterine prolapse and vaginal dome vaginally. Adv Urol. 2009;19(13):1074-9.

10. Mellier G, Gertych W, Lamblin G, Chabert P, Mathevet P. Suspension of the bottom of the vagina by posterior transobturator strip. Gynecol Obstet Fertil. 2007;35(7):625-31.

11. Nayama M, Idi N, Garba M, Sahabi S, Oumara M, Guedé $\mathrm{S}$, et al. Genital prolapse in a reference maternity hospital in Niger: Retrospective study of 336 cases in 3 years. Afr Soci Gynecol-Obstet. 2014;15(1):13-8.

12. Guillibert F, Chêne G, Fanget C, Huss M, Seffert P, Chauleur C. Risk factors for prosthesis exposure in vaginal genital prolapse cures. Gynecol Obstet Fertil. 2009;37(6):470-5.

13. Rathat G, Yazbeck C, Ebrard M, Guglielminotti J, Levin I, Madelenat P. Surgical treatment of prolapse of the elderly. About a continuous series of 43 cases. Gynecol Obstet Fertil. 2008;36(7):743-7.

14. Tebeu PM, Fomulu JN, Nana Njotang P, Petignat P, Tcheliebou JM, Kouam L, et al. Efficacy of vaginal hysterectomy for benign conditions in a semi-urban hospital: report from Maroua-Cameroon. Trop Doct. 2009;39(4):2000-5.

15. Lucot JP, Bot-Robin V, Giraudet G, Rubod C, Boulanger L, Dedet B, et al. Place of prosthetic material in the treatment of vaginal prolapse. Gynecol Obstet Fertil. 2011;39(4):232-44.

16. Le Normand L, Cosson M, Cour F, Deffieux X, Donon L, Ferry P, et al. Recommendations for clinical practice: Summary of recommendations for the surgical treatment of non-recurrent female genital prolapse by AFU, CNGOF, SIFUD-PP, SNFCP and SCGP. Progress Urol. 2016;26(1):51-7.

17. Mansoor A, Campagne S, Comou C, Goujon N, Cerisier S, Savary D, et al. Should the uterus be kept during the prolapse cure? Reflections from anatomical pathological results. Gynecol Obstet Fertil. 2013;41(2):80-4.

18. Delarue E, Collinet P, Sabban F, Lucot JP, Cosson M. Treatment of genital prolapse in young women: vaginal route or laparoscopic route? Gynecol Obstet Fertil. 2008;36(10):1043-9.

19. Demaria F, Boquet B, Bricou A, Benifla JL. For or against systematic hysterectomy during prolapse cures. Gynecol Obstet Fertil. 2006;34(11):1084-6.

20. Niro J, Philippe AC, Jaffeux P, Amblard J, Velemir I, Savary D, et al. Postoperative pain after vaginal genital prolapse treatment with or without prosthetic reinforcement. Gynecol Obstet Fertil. 2010;38(11):648-52.

21. Cravello L, Bretelle F, Cohen D, Roger V, Giuly J, Blanc B. Vaginal hysterectomy: about a series of 1,008 procedures. Gynecol Obstet Fertil. 2001;29(4):288-94.

22. Dia A, Ka O, Dieng M, Touré CT. Vaginal hysterectomy for hysterocele (report of 36 cases). Dakar Med. 2001;46(2):144-7.

23. Chene G, Tardieu AS, Savary D, Krief M, Boda C, Anton-Bousquet MC, et al. Anatomical and functional results of the McCall culdoplasty in the prevention of enteroceles and prolapse of the vaginal vault after vaginal hysterectomy. Int Urogynecol J. 2008;19(7):1007-11.

24. Cortesse A, Cardot V, Basset V, Le Normand L, Donon L. Treatment of urinary incontinence associated with genital prolapse: Recommendations for clinical practice. Adv Urol. 2016;26(1):589-97.

25. Deval B. Hysterocolpectomy with colpocleisis for massive genital prolapse in women over 70 years of age. Eur J Obstet Gynecol Reprod Biol. 2005;123(2):249-53.

26. Pizzoferrato AC, Bui C, Fauconnier A, Bader G. Uterine prolapse exteriorized on pregnant uterus. Preand postnatal care. Gynecol Obstet Fertil. 2013;41(7):467-70. 
27. Sergent F, Equy V, Rosier P, Hoffmann P. Surgical treatment for cystoceles via the low route and stress urinary incontinence: for two-stage surgery. Gynecol Obstet Fertil. 2011;39(10):590-3.

28. Marpeau L. Treat urinary incontinence at the same time as prolapse? Gynecol Obstet Fertil. 2011;39:586.

29. Boukerrou M, Mesdagh P, Yahi H, Crépin G, Robert $\mathrm{Y}$, Cosson M. MRI assessment of prolapse surgeries. Obstet Fertil Gynecol. 2006;34(11):1024-8.

30. Letouzey V, Fritel X, Pierre F, Courtieu C, Marès P, de Tayrac R. What information should be given to a patient before prolapse surgery? Gynecol Obstet Fertil. 2010;38(4):255-60.

Cite this article as: Diallo A, Sy T, Balde IS, Bah IK, Conte I, Diallo IM, et al. Outcome of surgical management of genital prolapse in the obstetric gynecology department of the Ignace Deen Hospital in Conakry, Guinea. Int J Reprod Contracept Obstet Gynecol 2020;9:2131-7. 